УДК 630.61

\title{
АНАЛИЗ ЗЕМЛЕУСТРОЙСТВА ЛЕСНОГО ФОНДА
}

\author{
Пасько Ольга Анатольевна', \\ pasko@agrophys.ru
}

\author{
Захарченко Александр Викторович², \\ zakh.al.vic@yandex.ru
}

\author{
Ковязин Василий Федорович ${ }^{3}$, \\ vfkedr@mail.ru \\ 1 Агрофизический научно-исследовательский институт, \\ Россия, 195220, Санкт-Петербург, Гражданский пр., 14. \\ 2 Тюменский научный центр Сибирского отделения Российской академии наук, \\ Россия, 625026, г. Тюмень, ул. Малыгина, 86. \\ 3 Санкт-Петербургский горный университет, \\ Россия, 199106, г. Санкт-Петербург, Васильевский остров, 21 линия, 2.
}

\begin{abstract}
Актуальность исследования связана с приоритетным вниманием государства к использованию леса в качестве главного воспроизводимого природного ресурса России.

Цель: анализ сложившегося пространственного деления земель лесного фонда.

Объекты: земли лесного фонда Томской области, разбитые на районы, лесничества и участковые лесничества по принципу трехуровневого иерархического деления
\end{abstract}

Методы: абстрактно-логический, аналитический и математического моделирования. Рабочая гипотеза предполагает, что площадь лесных участков зависит от значения единицы масштаба по степенному закону, а коэфффициент при логарифрме функции отражает диапазон изменения масштабной размерности. Впервые использована проблема изменяющегося масштаба применительно к анализу землеустройства лесничеств.

Результаты. Изучена иерархическая структура территориального деления земель лесного фонда. В иелом площади участковых лесничеств Томской области меняются в пределах 282-2332087 га. Однофакторный дисперсионный анализ площадей показывает низкую, менее 1 \%, вероятность нулевой гипотезы. Построенный на следующем этапе исследования профиль желательности выявил критическое значение средней площади, равной 71255 га, которому участки соответствуют с вероятностью 63 \%. Закономерности распределения суммарной площади лесов по лесничествам отличаются от нормального. Ее генеральное среднее значение равно 175000 га, площади хвойных лесов по лесничествам - 6000 га, лиственных лесов 11000 га. В целом площади хвойных лесов по лесничествам не превышают 8000 га, лиственных сосредоточены в диапазоне 4000-10000 и 16000-20000 га. Также неоднородно распределение запаса древесины. Суммарная площадь лесов по лесничествам распределена неравномерно, ее распределение близко к логнормальной модели. Наибольшее число площадей лесничеств сосредоточено в интервале до 15 тыс. га. Очень редко встречаются крупные участки (более 30 тыс. га). Высока фрагментарность хвойных лесов. Модальный размер участка составляет от двух до четырех тысяч гектаров. Крупные массивы леса встречаются достаточно редко. Распределение площадей лиственных лесов полимодально и разделяется на три части: до 2 тыс. га, 4-120 тыс. га, 14-20 тыс. га, что указывает на наличие лесов малых и средних площадей, а также крупных лесных массивов. Один массив леса относится к очень крупному (более 32 тыс. га). Суммарный запас древесины со-

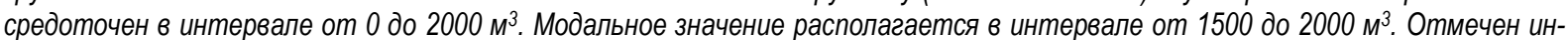
тервал 3000-3500 м³. В единичных случаях выявлены очень высокие запасы древесины (5500 м³). Запас древесины лиственных лесов, как и в случае с площадями, полимодален. Выделяется модальный интервал с очень низким запасом древесины - по-

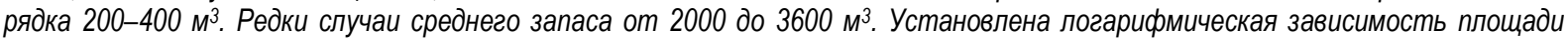
лесничества от порядкового номера выдела в упорядоченной по убыванию площади последовательности лесничеств. Коэфьфициент при логарифрме зависит от группы лесничеств (очень большие, большие, средние, малье). Аналогичная закономерность показана для участковых лесничеств. Установлено явное нарушение иерархии пространственного деления при выделении малых лесничеств, объяснимое экономической причиной. Иерархический анализ структуры естественной агрегации лесничеств по площади показал наличие пяти вложенных уровней неоднородности и, соответственно, пяти групп кластеров. В зависимости от уровня разделения в кластерном анализе выделяются девять иерархических уровней площадных размеров лесничеств, а уровень их раздела пропорционален масштабу - чем меньше, тем крупнее масштаб исследования. Это должно отражаться в инфрормации о состоянии лесничеств кластеров C1-С3 (очень крупнье и крупнье) и С4, С5 (средне- и мелкоразмерные) для выработки эфффективных управленческих решений.

\section{Ключевые слова:}

Лесной фонд, MAUP, лесничества, площадь, иерархическое деление.

\section{Введение}

Актуальность темы исследования определяется ценностью леса как основного воспроизводимого природного ресурса России [1].
Устойчивое лесопользование предполагает использование лесов и лесных площадей способами и интенсивностью [2], которые в полной мере обеспечивают сохранение биологического разнообразия, 
жизнеспособности, продуктивности и способности к самовозобновлению [3]. Основой освоения лесов [4], их охраны [5] и оценки [6] является лесное планирование. При его проведении учитывают комплекс параметров, в первую очередь, особенность структуры леса и лесорастительные условия; перспективы развития инфраструктуры при непрерывном пользовании древесиной и экономическую доступность лесных ресурсов [7].

В Лесном кодексе предусмотрены четыре уровня лесного планирования: федеральный (государственная инвентаризация лесов), региональный (лесной план субъекта РФ), лесничества или лесопарка (лесохозяйственный регламент) и лесного участка, переданного в лесопользование (проект освоения лесов) [8].

Использование лесного фонда предполагает межевание лесных земель на кварталы, участковые и районные лесничества. При разделении этих хозяйственных единиц учитывают наличие действующих и проектируемых объектов инфраструктуры лесодобычи и деревообрабатки. Структуру пространственной организации лесных земель устанавливают с учетом их зонирования по планируемому освоению, видам использования и объему вырубаемой спелой древесины.

Базовые принципы территориального планирования лесного фонда регламентирует Лесоустроительная инструкция [9], которая определяет размер лесного квартала, средний размер лесотаксационного выдела и т. д. Учитывается комплекс организационнотехнических показателей, отражающих фрагментарность лесного массива: минимальная площадь спелого леса среди молодняка, не покрытые лесом земли; наличие дорог, просек, сенокосов, линий электропередач и других нелесных земель, а также неиспользуемые земли.

Для учета лесных земель и проведения таксационных и лесохозяйственных работ лесной фонд лесничества разделяют на кварталы, площадью 25-3000 га, в зависимости от категории лесов $\lceil 10\rceil$, каждый лесной квартал - на лесотаксационные выделы, относительно однородные по почвенно-грунтовым условиям произрастания, возрасту и составу древесной растительности.

Такое межевание земель лесного фонда позволяет проводить в лесном квартале комплекс мероприятий по использованию, охране, защите и воспроизводству лесов в пределах нормативных допусков [11].

В международной практике лесопользования широко используют геоинформационные системы, дистанционное зондирование Земли $[12,13]$ и статистический анализ данных. Особое внимание уделяют надежности получаемой информации. Так, в Европейском Союзе для сравнительного анализа систем территориального управления и пространственного планирования лесных земель применяют исследование на основе метода MAUP (Modifiable Areal Unit Problem - проблема изменяющегося масштаба) [14]. Исследования проходят в рамках международной программы ESPON 2020 [15] и касаются таких сфер, как кадастр [16], градостроительство [17], сельскохо- зяйственное производство [18, 19], здравоохранение [20-23], демография [24], туризм [25], экология $[26,27]$ и др.

Метод MAUP разработан в ходе решения проблемы агрегации данных [28], вызванной спецификой пространственного деления земель и масштабом исследования. Установлена зависимость среднеарифметических и среднеквадратических значений параметров системы от масштаба исследования и формы разбиения земель [29]. Признание чувствительности результатов пространственного анализа к выбору единиц измерения данных имеет решающее значение для характеристики территорий с минимальным смещением и позволяет избегать ложных взаимосвязей и противоречивых результатов.

Естественные процессы в виде вложенных циклов неоднородности определяют естественную иерархическую структуру географического пространства. Например, вейвлет-анализ мощности верхнего почвенного горизонта траншеи [30] и колебаний температуры поверхностных слоев выявил несколько иерархических уровней сложно увязанных между собой волн [31], являющихся причиной случайности изучаемых явлений.

Что касается лесопользования, следует иметь в виду уникальность ландшафтно-географических, территориальных и экономических условий, сложившихся в регионах, которые влияют на территориальное деление лесных земель для их эффективного воспроизводства, охраны и защиты [32]. Соответственно, уникальны иерархическая структура управления лесопользованием и региональное территориальное деление земель лесного фонда. Многомасштабность размеров структурных единиц лесного фонда обусловлена объективными и случайными факторами. Она вызывает появление проблемы MAUP как источника статистической погрешности, способной существенно влиять на результаты проверки статистических гипотез.

Целью работы является анализ землеустройства лесного фонда с учетом разделения территории на два уровня управления: кварталы и участковые лесничества.

Научная новизна заключается в разработке методического подхода к выявлению иерархической структуры управления лесопользованием и агрегации пространственной информации.

В статье проведен пространственный автокорреляционный анализ территориальных параметров лесного фонда для показа возможностей влияния MAUP на результаты лесопользования. Рассмотрено пространственное соответствие двух уровней иерархической организации земель лесного фонда - районные лесничества (первый уровень) и составляющие территорию лесничества (второй уровень) [33].

Практический смысл исследования заключается в сравнении традиционного статистического подхода с учетом и без учета MAUP к сложившемуся распределению земельных участков лесного фонда разных иерархических уровней. 


\section{Материалы и методики исследования}

Объектом исследования служат земли лесного фонда Томской области (рис. 1), разбитые на административные районы, районные и участковые лесничества по принципу трехуровневого иерархического деления. Предмет исследования - пространственные характеристики 75 участковых лесничества, расположенных в 26 районных лесничествах и в 17 административных районах Томской области.

В качестве исходного материала использованы данные сайта Департамента лесного хозяйства Томской области [34].

Проведен анализ легитимности такого территориального деления и соотношения иерархических уровней в зависимости от масштаба [33]. Использован иерархический кластерный анализ площадей лесничеств на основе расчета евклидового расстояния.

Применен комплекс методов, включающий абстрактно-логический, аналитический, картографический и метод математического моделирования $[35,36]$. С помощью программного пакета Statistica проверена вероятность нуль-гипотезы о случайном характере территориального деления площадей лесничеств, расположенных на территории Томской области. Рабочая гипотеза предполагает, что площадь лесных участков зависит от значения единицы масштаба по степенному закону, а коэффициент при логарифме функции отражает диапазон изменения масштабной размерности.

Таблица 1. Пространственное деление лесных земель Томской области

Table 1. Spatial division of forest lands in the Tomsk region

\begin{tabular}{|c|c|c|c|}
\hline $\begin{array}{c}\text { Административный район } \\
\text { Administrative district }\end{array}$ & $\begin{array}{c}\text { Районное лесничество } \\
\text { Regional forestry }\end{array}$ & $\begin{array}{c}\text { Участковое лесничество } \\
\text { Local forestry }\end{array}$ & $\begin{array}{c}\text { Общая площадь, га } \\
\text { Total area, ha }\end{array}$ \\
\hline \multirow{2}{*}{$\begin{array}{c}\text { Александровский } \\
\text { Alexandrovsky }\end{array}$} & \multirow{2}{*}{$\begin{array}{l}\text { Александровское } \\
\text { Alexandrovskoe }\end{array}$} & Александровское/Alexandrovskoe & 2332087 \\
\hline & & Стрежевское/Strezhevskoe & 260587 \\
\hline$\ldots$ & $\ldots$ & $\ldots$ & $\ldots$ \\
\hline Каргасокский/Kargasoksky & Васюганское /Vasyuganskoe & Васюганское/Vasyuganskoe & 2983376 \\
\hline \multirow{7}{*}{$\begin{array}{l}\text { Верхнекетский } \\
\text { Verkhneketsky }\end{array}$} & \multirow{7}{*}{$\begin{array}{l}\text { Верхнекетское } \\
\text { Verkhneketskoe }\end{array}$} & Катайгинское/Kataiginskoe & 676175 \\
\hline & & Максимоярское/Maksimoyarskoe & 523972 \\
\hline & & Клюквинское/Klyukvinskoe & 286376 \\
\hline & & Дружнинское/Druzhninskoe & 891171 \\
\hline & & Лисицинское/Lisitsinskoe & 1316889 \\
\hline & & Белоярское/Beloyarskoe & 331660 \\
\hline & & Ягоднинское/Yagodninskoe & 278958 \\
\hline \multirow{3}{*}{$\begin{array}{l}\text { Зырянский } \\
\text { Zyryansky }\end{array}$} & Зырянское/Zyryanskoe & Зырянское/Zyryanskoe & 51047 \\
\hline & \multirow{2}{*}{$\begin{array}{l}\text { Каргасокское } \\
\text { Kargasokskoe }\end{array}$} & Окунеевское/Okuneevskoe & 140529 \\
\hline & & Чердатское/Cherdatskoe & 66739 \\
\hline \multirow{7}{*}{$\begin{array}{c}\text { Каргасокский } \\
\text { Kargasoksky }\end{array}$} & \multirow{7}{*}{$\begin{array}{l}\text { Каргасокское } \\
\text { Kargasokskoe }\end{array}$} & Большегривское/Bolshegrivskoe & 247639 \\
\hline & & Верх-Тымское/Verkhne-Tymskoe & 2325120 \\
\hline & & Каргасокское/Kargasokskoe & 718345 \\
\hline & & Нюрольское/Nyurolskoe & 582993 \\
\hline & & Тевризское/Tevrizskoe & 602716 \\
\hline & & Тымское/Tymskoe & 270166 \\
\hline & & Чижапское/Chizhapskoe & 675818 \\
\hline$\ldots$ & $\ldots$ & $\ldots$ & $\ldots$ \\
\hline \multirow{9}{*}{$\begin{array}{l}\text { Молчановский } \\
\text { Molchanovsky }\end{array}$} & Асиновское/Asinovskoe & Батуринское/Baturinskoe & 27994 \\
\hline & Кривошеинское/Krivosheinskoe & Красноярское/Krasnoyarskoe & 34393 \\
\hline & Асиновское/Asinovskoe & Батуринское/Baturinskoe & 27994 \\
\hline & \multirow{5}{*}{$\begin{array}{l}\text { Молчановское } \\
\text { Molchanovskoe }\end{array}$} & Молчановское/Molchanovskoe & 136279 \\
\hline & & Сулзатское/Sulzatskoe & 130703 \\
\hline & & Суйгинское/Suiginskoe & 162503 \\
\hline & & Елтыревское/Eltyrevskoe & 728578 \\
\hline & & Шудельское/Shudelskoe & 533660 \\
\hline & Улу-Юльское/Ulu-Yulskoe & Улу-Юльское/Ulu-Yulskoe & 60650 \\
\hline$\ldots$ & $\ldots$ & $\ldots$ & $\ldots$ \\
\hline \multirow{12}{*}{$\begin{array}{l}\text { Томский } \\
\text { Tomsky }\end{array}$} & \multirow{5}{*}{$\begin{array}{l}\text { Корниловское } \\
\text { Kornilovskoe }\end{array}$} & Томско-Обское/Tomsko-Obskoe & 45962 \\
\hline & & Егоровское/Egorovskoe & 124778 \\
\hline & & Прикульское/Prikulskoe & 58401 \\
\hline & & Северо-Алтайское/Severo-Altayskoe & 72779 \\
\hline & & Корниловское/Kornilovskoe & 54355 \\
\hline & Кривошеинское/Krivosheinskoe & Красноярское/Krasnoyarskoe & 58099 \\
\hline & \multirow{4}{*}{$\begin{array}{l}\text { Тимирязевское } \\
\text { Timiryazevskoe }\end{array}$} & Моряковское/Moryakovskoe & 38364 \\
\hline & & Богородское/Bogorodskoe & 29752 \\
\hline & & Темерчинское/Temerchinskoe & 79798 \\
\hline & & Калтайское/Kaltayskoe & 96595 \\
\hline & \multirow{2}{*}{$\begin{array}{l}\text { Tомское } \\
\text { Tomskoe }\end{array}$} & Богашевское/Bogashevskoe & 34381 \\
\hline & & Межениновское/Mezheninovskoe & 19230 \\
\hline \multirow{3}{*}{$\begin{array}{c}\text {... } \\
\text { Шегарский } \\
\text { Shegarsky }\end{array}$} & $\ldots$ & $\ldots$ & $\ldots$ \\
\hline & \multirow{2}{*}{ Шегарское/Shegarskoe } & Шегарское/Shegarskoe & 124903 \\
\hline & & Иловское/Ilovskoe & 184986 \\
\hline
\end{tabular}




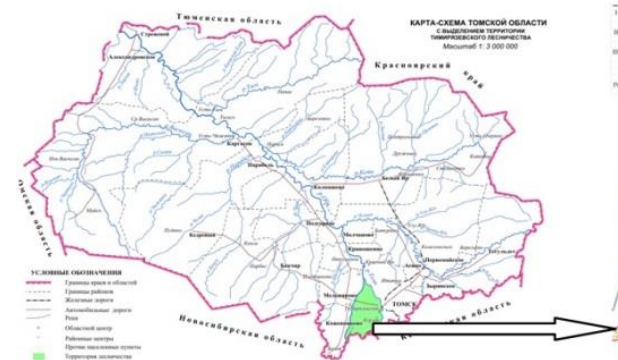

$\mathbf{A} / \mathbf{A}$

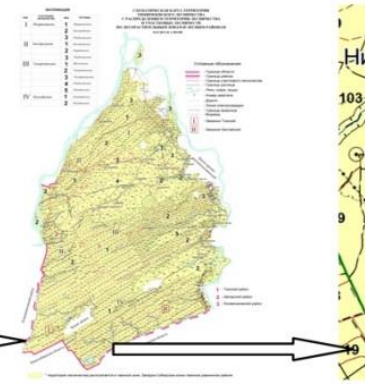

$\mathbf{5} / \mathbf{B}$

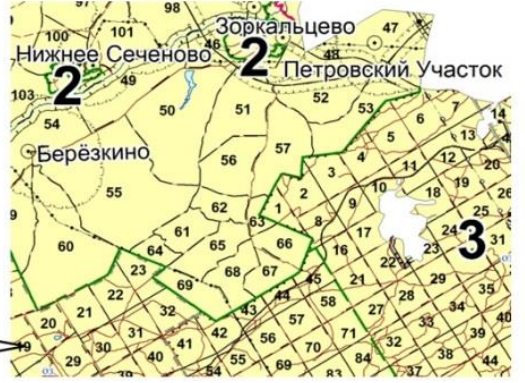

$\mathrm{B} / \mathrm{C}$

Pис. 1. Пример иерархической организации земель лесного фонда Томской области: А) положение Тимирязевского районного лесничества на карте области; Б) его схема; В) фрагмент лесных земель с указанием урочищ и лесных кварталов [34]

Fig. 1. Example of hierarchical organization of forest lands in the Tomsk region: A) position of Timiryazevsky district forestry on the map of the region; B) its scheme; C) fragment of forest land indicating tracts and forest blocks [34]

\section{Результаты исследования и обсуждение}

Предварительный анализ размеров, форм и географического положения лесничеств показывает, что осью симметрии по отношению к форме выделов является река Обь. С продвижением на северо-запад, запад и восток от областного центра (г. Томск) размеры лесничеств увеличиваются, а форма вытягивается.

В ходе анализа выявлена иерархическая структура территориального деления земель лесного фонда (табл. 1). Территории некоторых лесничеств расположены либо в одном административном районе, либо сразу в нескольких. Имеются лесничества с большим числом лесных участков (Каргасокское, Верхнекетское и Тимирязевское) и с одним-двумя участками (Васюганское, Зырянское, Александровское и Томское). Северные лесничества, например, Васюганское и Александровское, имеют большую площадь земель, но поделены на один-два участка в связи с труднодоступностью и заболоченностью территории.

Однофакторный дисперсионный анализ площадей показывает низкую, менее $1 \%$, вероятность нулевой гипотезы. Проверена альтернативная гипотеза о том, что распределение площадей по участкам лесничеств не случайно. Изучен расчетный объем изъятия древесины по лесничеству как фактор, учитываемый при разбиении территории. Показана неоднородность распределения по всем изученным параметрам (рис. 2). Средняя площадь лесничества с вероятностью $63 \%$ равна 71255 га.

Распределение частоты встречаемости значений суммарной площади лесов в лесничестве значительно отличается от нормального распределения (рис. 2, А). Среднее значение суммарной площади лесов составляет 175000 га; площади лесничества - не более 15000 га. Генеральное среднее значение площади хвойных лесов равно 6000 га (рис. 2, Б), лиственных - 11000 га (рис. 2, В) Основная площадь хвойных древостоев по лесничествам не превышает 8000 га, лиственных древостоев находится в интервалах 4000-10000 и 16000-20000 га. Распределение частоты встречаемости запаса древесины также крайне неоднородно.

Распределение суммарной площади лесничеств близко к логнормальной модели (рис. 2, А): максимум значений находится в интервале до 15 тыс. га; единичны участки леса более 30 тыс. га. Высока фрагментарность площадей хвойных лесов (рис. 2, Б); модальный размер участка составляет от двух до четырех тысяч гектаров; крупные массивы леса встречаются редко. Распределение значений площади лиственных лесов полимодально (рис. 2, В) и разделяется на три части: до двух тыс. га, 4-120 тыс. га, 14-20 тыс. га. Это указывает на наличие лесных участков малых, средних и больших площадей; один массив леса является очень крупным (более 32 тыс. га).

Суммарный запас древесины в лесничестве (рис. 2 , Д) в среднем не превышает $2000 \mathrm{~m}^{3}$. Модальное значение находится в интервале от 1500 до $2000 \mathrm{~m}^{3}$. Отмечен интервал 3000-3500 м³. В единичных случаях выявлены очень высокие запасы древесины $\left(5500 \mathrm{~m}^{3}\right)$. Диаграммы распределения общего запаса древесины (рис. 2, Г) и площади хвойных лесов (рис. 2, Б) в лесничествах указывают на низкие значения их запаса. Максимум достигает значений 2000-2200 м³. Запас древесины лиственных лесов (рис. 2, Е), как и в случае с площадями, полимодален. Выделяется модальный интервал с очень низким запасом древесины (200-400 м³), редки случаи среднего запаса древесины в лесничествах (2000 до $\left.3600 \mathrm{~m}^{3}\right)$.

Следует отметить, что площадные размеры лесничеств неоднородны. Самыми крупными по площади являются Каргасокское (5630065 га) и Верхнекетское (4305201 га) лесничества. На два порядка меньше площади Кривошеинского (58100 га) и Томского лесничеств (27500 га), на три порядка -Тимирязевского (9900 га), на четыре - Шегарского лесничества (600 га). Медианное значение площади участковых лесничеств в Томской области равно 140529 га.

При интерпретации полученной закономерности изменения площадей лесничеств ожидаема линейная зависимость их роста с ростом номеров в упорядоченной по площади последовательности. Согласно MAUP, при изменении единицы масштаба, зависимость изменения площадей следует степенному закону. Для упрощения визуализации степенные кривые можно линеаризовать с использованием логарифмов. Для ответа на вопрос «Какие площадные размеры наиболее и наименее распространены?» построен график зависимости площади лесничества от порядкового номера в упорядоченной последовательности по ее размеру (рис. 3). 

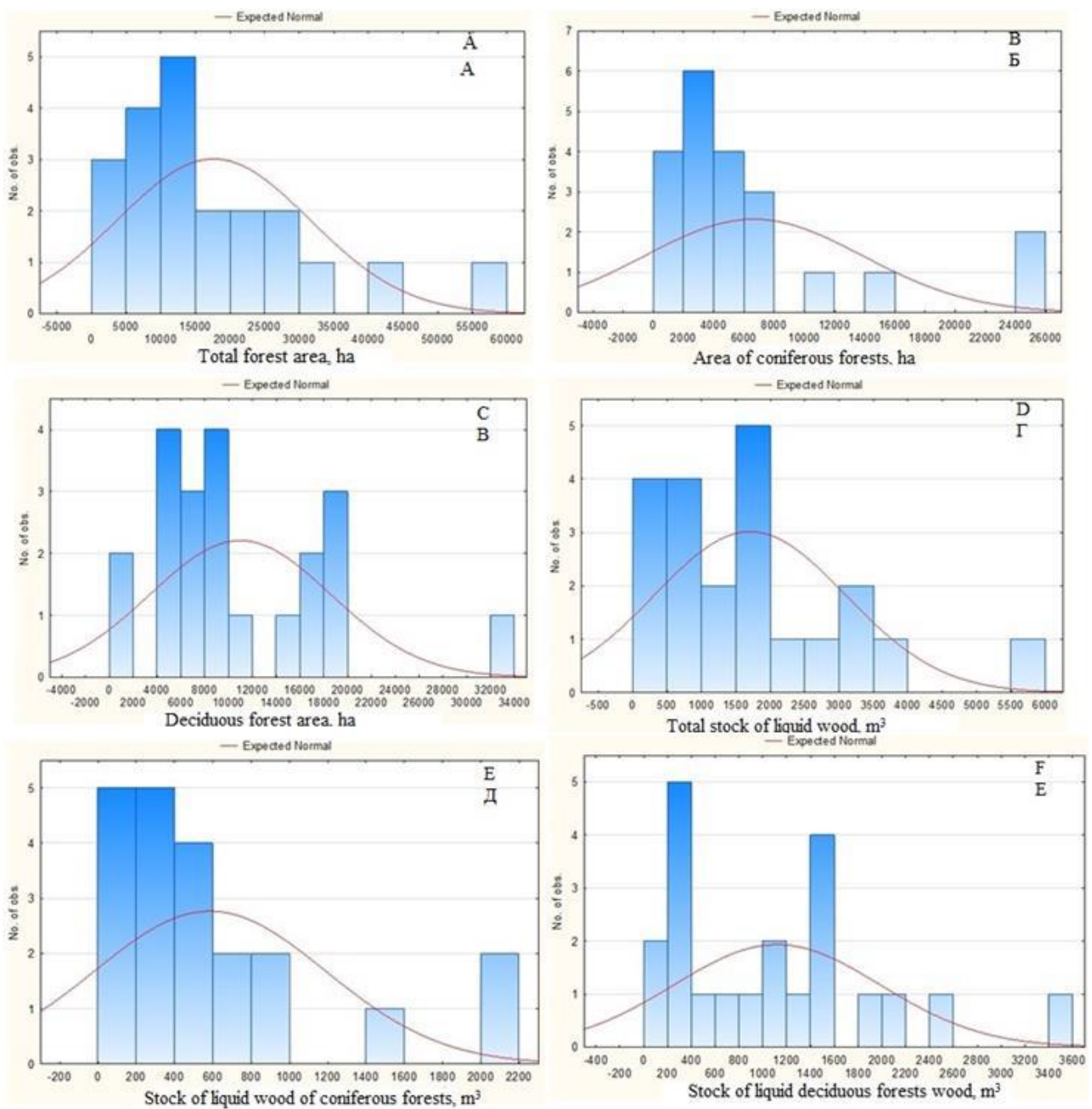

Pис. 2. Распределение частоты встречаемости различных показателей в лесничестве: A) суммарная площадь лесов (га); Б) площуадь хвойных лесов (га); В) площуадь лиственных лесов (га); Г) общий запас древесины (м $\left.{ }^{3}\right)$; Д) запас древесины хвойных пород $\left(\mathrm{M}^{3}\right) ;$ E) запас древесины лиственных пород $\left(\mathrm{M}^{3}\right)$

Fig. 2. Distribution of various indicators occurrence frequency in the Tomsk region forestries: A) total forest area (ha); B) coniferous forest area (ha); C) deciduous forest area (ha); D) total wood stock $\left(\mathrm{m}^{3}\right)$; E) coniferous wood stock $\left.\left(\mathrm{m}^{3}\right) ; \mathrm{F}\right)$ deciduous wood stock $\left(\mathrm{m}^{3}\right)$

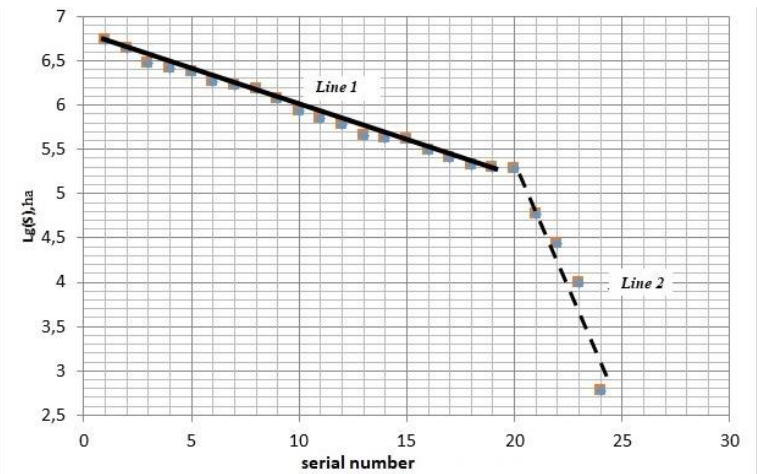

Рис. 3. Зависимость логарифма площади лесничеств от номера в упорядоченной последовательности значений площуади лесничеств

Fig. 3. Dependence of the logarithm of the area of forest areas on the number in the ordered sequence of values of the area of forest areas

График, представленный на рис. 3, включает два отрезка: Line 1 (17 объектов) и Line 2 (5 объектов), что свидетельствует об их существенном различии и объективности фактора разделения. На наш взгляд, к отрезку 1 относятся лесничества, образованные в соответствии с нормативными инструкциями (рис. 4, А) при R2=0,99. Отрезок 2 графика характеризует лесничества сверхмалого размера (рис. 4, В), к примеру, выделенные вблизи населенных пунктов для удобства контроля территории $(\mathrm{R} 2=0,92)$. Заметим, что коэффициенты углов наклона отрезков 1 и 2 к оси абсцисс $(-0,8$ и $-0,577)$ различаются в 7,5 раз, т. е. малые лесничества выбиваются из общей схемы территориального деления.

Территории лесничеств разделены на участковые лесничества и являются иерархическими системами, вложенными друг в друга как матрешки (рис. 4, C). Наклон зависимости Line 3 почти в два раза меньше, чем Line 1 (рис. 5, A). Максимальный наклон у Line 2. Линии 1 и 3 пересекаются при значении 310 га $(\lg (S)=5,6)$ при достижении равенства площадей лесничества и участкового лесничества. После точки пересечения эти различия нивелируются. Как видно из pис. 5, B, С, по углам наклона Line 2 отличен от от- 
резков 1 и 3 ; пересечение между Line 2 и линиями 1 и 3 происходит только в крайних точках, что указывает на то, что сверхмалые лесничества (Line 2) находится в других условиях территориального масштабирования по сравнению с обычными и участковыми лесничествами
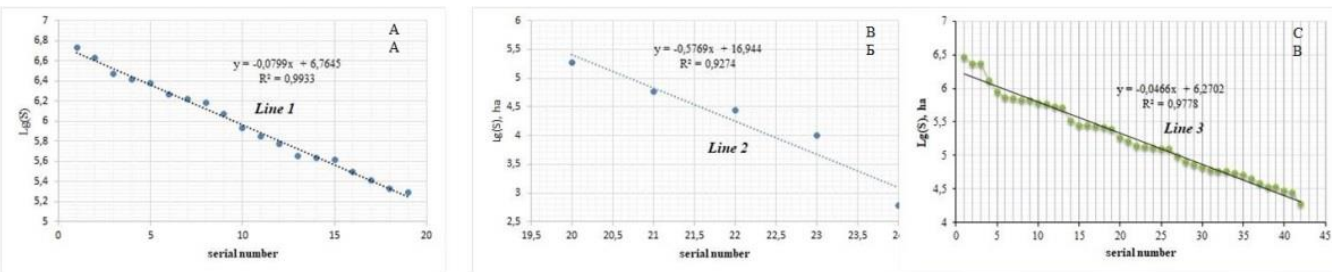

Рис. 4. Зависимость логарифма значений площади лесничества от порядкового номера в упорядоченной последовательности по значениям площади: А) лесничества обычных размеров по площади (отрезок 1); В) сверхмалые лесничества (отрезок 2); С) участковые лесничества (отрезок 3)

Fig. 4. Dependence of the forest area values logarithm on the ordinal number in the ordered sequence of the values of the area: A) forest areas of normal size by area (segment 1); B) ultra-small forest areas (segment 2); C) district forest areas (segment 3)
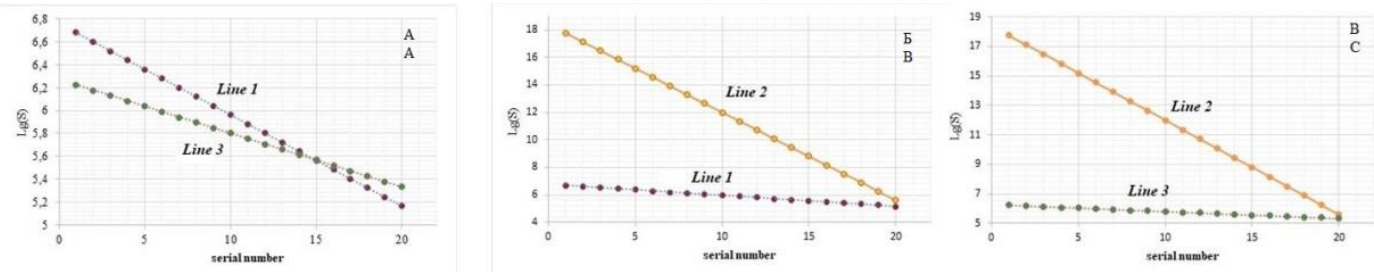

Рис. 5. Сопоставление наклонов зависимостей значений площади лесничества от номера лесничества в упорядоченной последовательности по значениям площади попарно: отрезки 1 и 3 (A); отрезки 1 и 2 (B); отрезки 2 и 3 (С). Условные обозначения-см. рис. 4.

Fig. 5. Comparison of the slopes of the dependencies of the forest area values on the number of the forest area in an ordered sequence by the values of the area in pairs: segments 1 and $3(A) ;$ segments 1 and $2(B) ;$ segments 2 and $3(C)$. Symbols-see Fig. 4.

Таким образом, с одной стороны наблюдается наложение объектов разных иерархических уровней организации пространственной структуры лесничеств; с другой стороны, имеется много лесничеств (площадью менее 310 га), выделенных в противоречии с общим естественным подходом к разделу земель лесного фонда. Столь явное нарушение иерархии пространственного деления при образовании малых лесничеств как территориальных единиц управления в области использования лесов объяснимо высокой стоимостью древесины и необходимостью контроля охраны, защиты и воспроизводства лесов вблизи населенных пунктов.

Для детализации принципов иерархического деления земель Лесного фонда на лесничества использован иерархический кластерный анализ. Результаты иерархического анализа структуры естественной агрегации лесничеств по площади представлены на рис. 6.

Группа мелкоразмерных лесничеств делится на две подгруппы: первая характеризуется интервалом площадей 260-286 тыс. га, а вторая - 19-185 тыс. га; вторая подгруппа включает две агрегации: 125-185 и 51-19 тыс. га. Агрегации формируют достаточно однородные по площадям лесничества.

В зависимости от уровня разделения в кластерном анализе выделяются девять иерархических уровней площадных размеров лесничеств (табл. 2), а уровень их раздела пропорционален масштабу - чем меньше, тем крупнее масштаб исследования.

Очевидно, что информация о состоянии лесов кластеров C1-C3 и кластеров C4, C5 (средне- и мелкораз- мерных лесничеств) должна существенно различаться. Следовательно, неправомерно проводить оценку лесоустроительных характеристик крупно- и мелкоразмерных кластеров едиными методами, что доказывает необходимость использования принципов MAUP при статистическом анализе характеристик лесных выделов для эффективного управления лесами.

Таблица 2. Уровень иерархии, количество кластеров и условия кластеризачии: значение Евклидова расстояния $\left({ }^{*} е 10^{6}\right)$ площадей (га) лесничеств и шкала соотношений масштабов (\%)

Table 2. Hierarchy level, number of clusters and clustering conditions: value of Euclidean distance $\left(* e 10^{6}\right)$ of areas (ha) of local forestry and heipht ratio (\%)

\begin{tabular}{|c|c|c|c|c|c|c|c|c|c|}
\hline $\begin{array}{l}\text { Параметр } \\
\text { Parameter }\end{array}$ & \multicolumn{9}{|c|}{ Значение/Value } \\
\hline $\begin{array}{l}\text { Уровень } \\
\text { иерархии } \\
\text { Hierarchy level }\end{array}$ & 1 & 2 & 3 & 4 & 5 & 6 & 7 & 8 & 9 \\
\hline $\begin{array}{l}\text { Количество } \\
\text { кластеров } \\
\text { Number of } \\
\text { clusters }\end{array}$ & 2 & 3 & 5 & 7 & 9 & 11 & 13 & 16 & 22 \\
\hline $\begin{array}{l}\text { Евклидово рас- } \\
\text { стояние }\left(* \mathrm{e} 10^{6}\right) \\
\text { Euclidean } \\
\text { distance }\left(* \mathrm{e} 10^{6}\right) \\
\end{array}$ & 1,2 & 0,8 & 0,5 & 0,18 & 0,04 & 0,03 & 0,02 & 0,01 & 0,008 \\
\hline \begin{tabular}{|l|} 
Шкала \\
соотношений, \% \\
Heipht ratio, \%
\end{tabular} & 52,9 & 35,1 & 19,6 & 7,1 & 3,1 & 2,5 & 1,9 & 1,0 & 0,5 \\
\hline
\end{tabular}




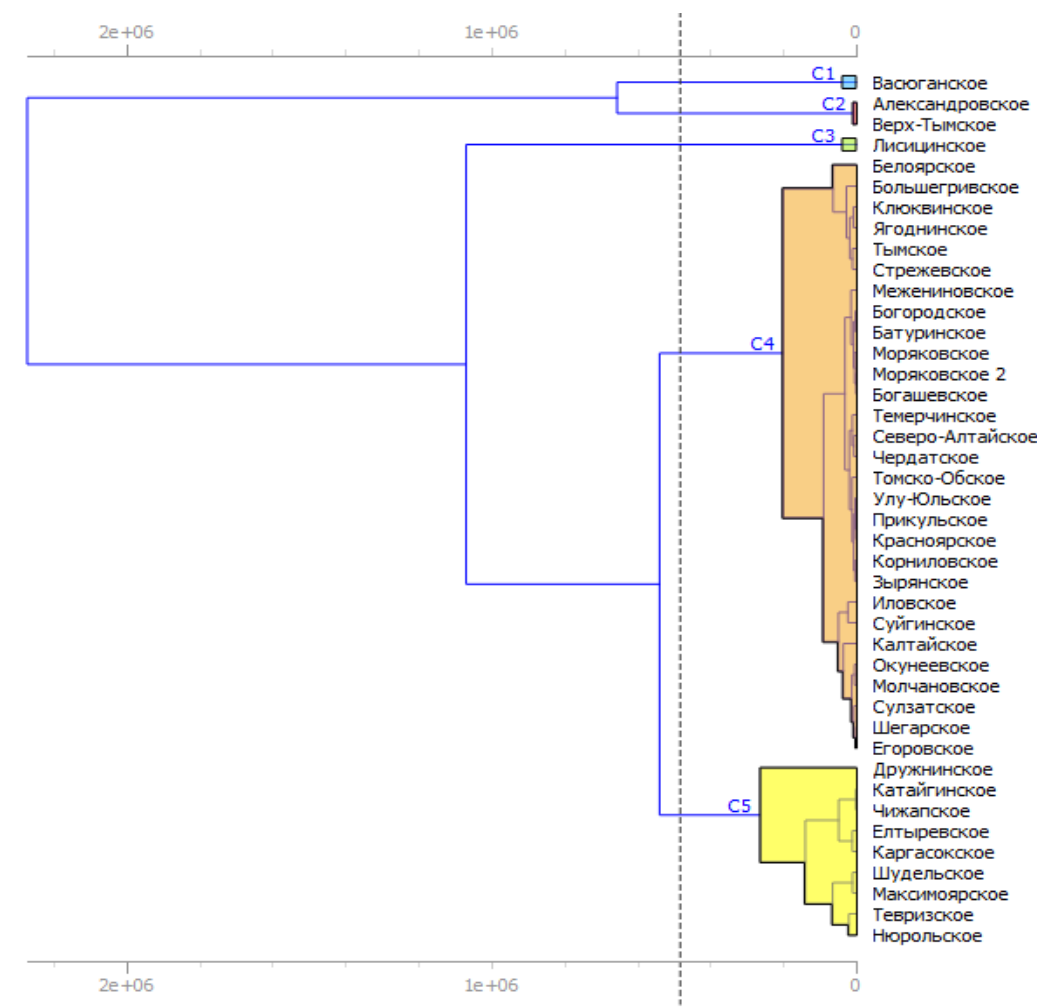

Рис. 6. Иерархический анализ структуры агрегации лесничеств по площади

Fig. 6. Hierarchical analysis of the structure of local forestry area aggregation

\section{Заключение}

В ходе исследования проверена гипотеза о том, что распределение площадей лесного фонда по лесничествам не случайно, а обусловлено социальноэкономическими факторами. Диапазон изменчивости площадей участковых лесничеств Томской области составляет 282-2332087 га. Ряд лесничеств расположены в одном административном районе, другие сразу в нескольких; имеются лесничества с высокой и низкой степенью фрагментации территорий. Критическое значение средней площади участка (71255 га) выявлено по профилю желательности с вероятностью 63 \%. Генеральное среднее значение суммарной площади лесов составляет 175000 га, площади хвойных древостоев по лесничествам - 6000 га, а лиственных 11000 га. Площадь хвойных лесов по лесничествам в основном не превышает 8000 га, лиственных сосредоточена в интервалах 4000-10000 га и 16000-20000 га. Распределение суммарной площади лиственных и хвойных лесов, а также запасов древесины по лесничествам отличается от нормального, что доказывает неслучайность разбиения территории.

Суммарная площадь земель лесного фонда по лесничествам распределена не равномерно и близка к логнормальной модели. Максимум площадей лесничеств сосредоточен в интервале до 15 тыс. га, очень редки крупные участки более 30 тыс. га. Высока фрагментарность хвойных лесов - модальный размер участка составляет от двух до четырех тысяч гектаров; крупные массивы редки. Распределение площадей лиственных лесов полимодально и разделено на три части: до 2 тыс. га, 4-120 тыс. га, 14-20 тыс. га.
Суммарный запас древесины сосредоточен в интервале до $2000 \mathrm{~m}^{3}$, модальное значение - в интервалах от 1500 до $2000 \mathrm{~m}^{3}$ и от 3000 до $3500 \mathrm{~m}^{3}$. Запас древесины лиственных лесов в лесничествах, как и в случае с площадями, полимодален - выделен модальный интервал с очень низким запасом - 200-400 м³; редки случаи среднего запаса - от 2000 до $3600 \mathrm{~m}^{3}$.

Логнормальное распределение общей площади лесничеств объяснимо логарифмической зависимостью площади выдела от его порядкового номера при упорядочивании ее по убыванию. Показано, что в соответствии с принципами проблемы изменяющегося масштаба (MAUP) площадные размеры лесничеств изменяются по степенному закону. Выявлено, что выделяются две группы объектов: обычные (17) и сверхмалые (5). Наклон линии зависимости сверхмалых наибольший. На порядок меньше наклон зависимости обычных размеров лесничеств. Участковые лесничества имеют наклон зависимости в 2 раза меньший, чем обычные лесничества. Следовательно, при переходе от одного иерархического уровня размеров лесничеств к другому масштаб исследования увеличивается кратно.

Установлено, что по размерам лесничества пересекаются с нижележащим иерархическим уровнем участковыми лесничествами в точке 310 га. Меньше этого размера лесничества и участковые лесничества не различаются.

Иерархический анализ структуры естественной агрегации лесничеств по площади показал наличие пяти уровней и, соответственно, пяти групп кластеров. В зависимости от уровня разделения в кластерном 
анализе выделяются девять иерархических уровней площадных размеров лесничеств, а уровень их раздела пропорционален масштабу - чем меньше, тем крупнее масштаб исследования - в полном соответствии с подходом MAUP.

\section{СПИСОК ЛИТЕРАТУРЫ}

1. Об утверждении основ государственной политики в области использования, охраны, защиты и воспроизводства лесов в Российской Федерации на период до 2030 года. Распоряжение Правительств Российской Федерации от 26 сентября 2013 года N 1724-p. URL: http://docs.cntd.ru/document/499047151 (дата обращения 02.10.2020).

2. Добрынин Д. Перспективы ведения лесного хозяйства с сохранением постоянного лесного покрова в Финляндии и в России // Устойчивое лесопользование. - 2019. - № 1 (57). C. $42-45$.

3. Kovyazin V.F., Romanchikov A.Yu., Pasko O.A. Comparative analysis of forest landscadastral appraisal estimated with regards to wood and food resources // IOP Conference Series: Earth and Environmental Science. - 2015. DOI: 10.1088/1755 1315/27/1/012039

4. Forest biodiversity, ecosystem functioning and the provision of ecosystem services / E.G. Brockerhoff, L. Barbaro, B. Castagneyrol, D.I. Forrester, B. Gardiner, J.R. González-Olabarria, Ph.O'B. Lyver, N. Meurisse, A. Oxbrough, H. Taki, I.D. Thompson // Biodiversity and Conservation. - 2017. - V. 26. - P. 3005-3035.

5. Петкау В.В. Гибкое и превентивное лесопользование в России // Вестник Челябинского государственного университета. Экономика. - 2009. - Вып. 1. - № 19 (157). - С. 127-132.

6. Добрынин Д. О проблеме выявления лесных участков, на которых возможно экономически выгодное интенсивное и экологически устойчивое лесопользование // Устойчивое лесопользование. - 2012. - № 2 (31). - С. 12-23.

7. Моисеев Н.А. Лесная экономика как отраслевая наука и ее прикладное значение в условиях реформ лесоуправления // Вестник МГУЛ - Лесной вестник. - 2008. - № 5. URL: https://cyberleninka.ru/article/n/lesnaya-ekonomika-kakotraslevaya-nauka-i-ee-prikladnoe-znachenie-v-usloviyah-reformlesoupravleniya (дата обращения: 02.10.2020).

8. Лесной кодекс Российской Федерации от 04.12.2006 N 200-Ф3 (ред. от 31.07.2020). URL: http://www.consultant.ru/document/ cons_doc_LAW_64299 (дата обращения: 02.10.2020).

9. Об утверждении Лесоустроительной инструкции (с изменениями на 6 февраля 2020 года: Приказ Министерства природных ресурсов и экологии Российской Федерации от 29 марта 2018 года N 122. URL: http://docs.cntd.ru/document/542621790 (дата обращения: 02.10.2020).

10. Об утверждении нормативов площади участковых лесничеств, лесных кварталов: Приказ Федерального агентства лесного хозяйства от 26 октября 2011 года N 447. URL: http://docs. cntd.ru/document/902321627 (дата обращения: 02.10.2020).

11. Taxation indices of forest stand as the basis for cadastral valuation of forestlands / V.F. Kovyazin, V.N. Belyaev, O.A. Pasko, A.Yu. Romanchikov // IOP Conference Series: Earth and Environmental Science. - 2014. - V. 21. - DOI: 10.1088/1755-1315/21/1/012026

12. Оценка состояния припоселковых кедровников Томской области с использованием данных дистанционного зондирования Земли / О.А. Пасько, О.С. Токарева, А.Д.А. Алшаиби, Т.Ю. Черникова, П. Кабраль // Известия Томского политехнического университета. Инжиниринг георесурсов. - 2019. Т. 330. - № 1. - С. 98-109.

13. Мониторинг состояния растительного покрова территории Центрального Ирака с использованием спутниковых данных Landsat-8 // O.C. Токарева, O.А. Пасько, С.М. Маджид, П. Кабраль // Известия Томского политехнического университета. Инжиниринг георесурсов. - 2020. - Т. 331. - № 6. C. $19-31$.

14. Shawna J.D., Bram D. The modifiable areal unit problem (MAUP) in physical geography // Progress in Physical Geography. - 2018. V. 31 (5). - P. 471-479. DOI: 10.1177/0309133307083294
Очевидно, что информация о состоянии лесов кластеров разных уровней иерархии должна существенно различаться по содержанию и проведению оценки лесоустроительных характеристик крупно- и мелкоразмерных кластеров и без учета MAUP некорректна для принятия эффективных управленческих решений.

15. Applied Research Projects. URL: https://www.espon.eu/appliedresearch (дата обращения: 02.10.2020).

16. Lee G.I., Cho W.K., Kim K.K. The problem of variable area units in hedonistic models of housing prices // Urban Geography Phys. 2016. - V. 37 (2). - P. 223-245. URL: https://dialnet.unirioja.es/ servlet/articulo?codigo=5466483 (дата обращения: 02.10.2020).

17. A global map of travel time to cities to assess inequality in accessibility in 2015 / D.D. Vas, A. Nelson, H.S. Gibson, V. Temperley, A. Lieber // Nature. - 2018. - V. 553 (7688). P. 333-336. DOI: 10.1038/nature25181.

18. Global distribution data for cattle, buffaloes, horses, sheep, goats, pigs, chickens and ducks in 2010 / M. Gilbert, G. Nicolas, G. Cinardi, T.P. van Boeckel, S.O. Vanwambeke, G.R.W.W. Wint // Scientific Data. - 2018. - V. 5 (1). - P. 1-11. DOI: 10.1038/sdata.2018.227.

19. Beckel V. Robinson intensive poultry farming in Thailand // Agricultural industry. URL: https://doi.org/10.1016/j.agee.2011.12.019 (дата обращения: 02.10.2020).

20. Geographic and statistic stability of deprivation aggregated measures at different spatial units in health research/ A. Cebrecos, M.F. Dominguez-Berjon, I. Duque, M. Franco // Applied geography. - 2018. - V. 95. - P. 9-18. URL: https://isiarticles. com/bundles/Article/pre/pdf/161686.pdf (дата обращения: 02.10.2020).

21. Truong P.N., Stein A. Hierarchically adaptable spatial regression model for the Association of aggregated health status data and environmental data // Spatial statistics. - 2018. - V. 23. - P. 36-51. URL: https://research.utwente.nl/en/publications/a-hierarchicallyadaptable-spatial-regression-model-to-link-aggre (дата обращения: 02.10.2020).

22. A spatial regression model for the disaggregation of areal unit based data to high-resolution grids with application to vaccination coverage mapping / C. Utazi, J. Thorley, V. Alegana, M. Ferrari, K. Nilsen, S. Takahashi // Statistical Methods in Medical Research. 2018. URL: https://doi.org/10.1177/0962280218797362 (дата обращения: 02.10.2020).

23. Geographical and statistical stability aggregated indicators of deprivation in various spatial units of health research / A. Cebrecos, M.F. Dominguez-Berjon, I. Duque, M. Franco, F. Escobar // Applied geography. - 2018. - V. 95. - P. 9-18.

24. Tatem A.J. World Pop, open data for spatial demography // Scientific Data. - 2017. - V. 4. URL: https://doi.org/10.1038/ sdata.2017.4 (дата обращения: 12.04.2020).

25. Digital trail of tourists in the cities: comparison of big data sources / M.H. Salas-Olmedo, B. Moya-Gomez, J.C. García-Palomares, J. Gutierrez // Tourism management. - 2018. - V. 66. - P. 13-25. URL: https://doi.org/10.1016/j.tourman.2017.11.001 (дата обращения: 02.10.2020).

26. Landscape heterogeneity as a surrogate biodiversity in mountain systems: which spatial analytical unit is most appropriate? / P. Garcia-Llamas, L. Calvo, M. de la Cruz, S. Suarez-Seoane // Environmental indicator. - 2018. - V. 85. - P. 285-294. URL: https://doi.org/10.1016/j.ecolind.2017.10.026 (дата обращения: 02.10.2020)

27. Wu J., Levin S.A. A patch-based spatial modeling approach: conceptual framework and simulation scheme // Ecological Modelling. - 1997. - V. 101. - P. 325-346.

28. Wang Ya., Di Q. Modifiable areal unit problem and environmental factors of COVID-19 outbreak // Sci Total Environ. - 2020. DOI: 10.1016/j.scitotenv.2020.139984. URL: https://pubmed.ncbi. nlm.nih.gov/32534259/ (дата обращения: 02.10.2020).

29. Nelson J.K., Brewer C.A. Evaluating data stability in aggregation structures across spatial scales: revisiting the modifiable areal unit problem // Cartography and Geographic Information Science. 2017. - V. 44 (1). - P. 35-50. URL: https://doi.org/10.1080/ 15230406.2015.1093431 (дата обращения: 02.10.2020) 
30. Захарченко А.В., Алексеев В.И., Ипатова Д.В. Иерархическая концепция неоднородности почв и планирование масштаба исследования // Известия Томского политехнического университета. Инжиниринг георесурсов. - 2016. - Т. 327. - № 4. C. 149-163.

31. Алексеев В.И. Вейвлет-анализ динамики изменений явления Эль-Ниньо - Ла-Нинья и его прогнозирование // Вестник Югорского Государственного Университета. - 2018. Вып. 3 (50). - С. 75-87. DOI: 10.17816/byusu2018075-87

32. Пасько О.А., Захарченко А.В., Поспелова Е.В. Дифференциация сельскохозяйственных угодий по площадям на примере Томского района // Известия Томского политехнического университета. Инжиниринг георесурсов. - 2019. - Т. 330. № 5. - C. 100-112.
33. Ковязин В.Ф., Мартынов А.Н., Беляева Н.В. Основы лесного хозяйства и таксация леса. - М.; СПб.; Краснодар: Лань, 2017. $238 \mathrm{c}$.

34. Департамент лесного хозяйства Томской области. URL: https://deples.tomsk.gov.ru (дата обращения: 02.10.2020).

35. Phillips J.D., Marion D.A. Biomechanical effects, lithological variations, and local pedodiversity in some forest soils of Arkansas // Geoderma. - 2005. - V. 124. - P. 73-89.

36. Pasko O.A., Kovyazin V.F., Zakharchenko A.V., Lebedeva N.A. Spatial organization of forestfund // IOP Conference Series: Earth and Environmental Science. - 2020. DOI: https://iopscience.iop. org/article/10.1088/1755-1315/574/1/012061

Поступила 13.01.2021 2.

\section{Информация об авторах}

Пасько О.A., доктор сельскохозяйственных наук, кандидат биологических наук, заведующая сектором экспериментальных агротехнологий Агрофизического научно-исследовательского института.

Захарченко A.B., доктор биологических наук, ведущий научный сотрудник Института проблем освоения Севера Тюменского научного центра Сибирского отделения Российской академии наук.

Ковязин В.Ф., доктор биологических наук, профессор кафедры инженерной геодезии Санкт-Петербургского горного университета. 
UDC 630.61

\title{
ANALYSIS OF LAND MANAGEMENT OF THE FOREST FUND
}

\author{
Olga A. Pasko', \\ pasko@agrophys.ru
}

\author{
Alexander V. Zakharchenko², \\ zakh.al.vic@yandex.ru \\ Vasily F. Kovyazin ${ }^{3}$, \\ vfkedr@mail.ru
}

\author{
${ }_{1}^{1}$ Agrophysical Research Institute, \\ 14, Grazhdansky avenue, St. Petersburg, Russia.
}

2 Tyumen scientific center of the Siberian branch of the Russian Academy of Sciences, 86, Malygin street, Tyumen, 625026, Russia.

3 Saint Petersburg mining University,

2, line 21, Vasilievsky island, Saint Petersburg, 199106, Russia.

The relevance of the research is related to the priority attention of the state to the use of forests as the main reproducible natural resource in Russia.

The aim of the research is to analyze the existing spatial division of forest lands.

Objects: lands of the forest fund of the Tomsk region, divided into districts, forest areas and district forest areas on the principle of threelevel hierarchical division

Methods: abstract-logical, analytical and mathematical modeling. The working hypothesis assumes that the area of forest plots depends on the value of the scale unit according to the power law, and the coefficient at the logarithm of the function reflects the range of changes in the scale dimension. For the first time, the problem of changing scale is used in relation to the analysis of land management in forest areas.

Results. The hierarchical structure of the territorial division of forest lands is revealed. In general, the area of local forest areas in the Tomsk region varies between 282-2332087 ha. Univariate variance analysis of areas shows a low probability of a null hypothesis (less than $1 \%)$. The desirability profile constructed at the next stage of the study revealed a critical value of the average area equal to $71255 \mathrm{ha}$, to which the plots correspond with a $63 \%$ probability. The patterns of distribution of the total forest area by forest areas differ from the normal one. Its general average value is 175000 ha, the area of coniferous forests in forest areas - 6000 ha, deciduous forests 11,000 ha. In general, the area of coniferous forests in forest areas does not exceed 8000 ha, deciduous forests are concentrated in the range of 4000-10000 and 16000-20000 ha. The distribution of wood stock is also heterogeneous. The total area of forests in forest areas is not evenly distributed, and its distribution is close to the lognormal model. The largest number of forest areas is concentrated in the range of up to 15000 ha. Very rarely there are large plots (more than 30000 ha). Fragmentation of coniferous forests is high. The modal size of the site is from two to four thousand hectares. Large areas of forest are quite rare. The distribution of deciduous forest areas is polymodal and is divided into three parts: up to 2000 ha, 4000-120000 ha, 14000-20000 ha, which indicates the presence of small and medium-sized forests, as well as large woodlands. One forest area is very large (more than 32000 ha). The total supply of liquid wood is concentrated in the range from 0 to $2000 \mathrm{~m}^{3}$. The modal value is within the range from 1500 to $2000 \mathrm{~m}^{3}$. The interval of 3000-3500 $\mathrm{m}^{3}$ is marked. In some cases, very high reserves of wood were found $\left(5500 \mathrm{~m}^{3}\right)$. The stock of liquid deciduous wood, as in the case of areas, is polymodal. There is a modal interval with a very low wood stock of the order of 200-400 $\mathrm{m}^{3}$. There are rare cases of an average stock from 2000 to $3600 \mathrm{~m}^{3}$. The logarithmic dependence of the forest area on the ordinal number of the allotment in the sequence of forest areas ordered in descending order of area is established. The logarithm coefficient depends on the group of forest areas (very large, large, medium, small). A similar pattern is shown for local forest districts. There is a clear violation of the hierarchy of spatial division in the allocation of small forest areas, explained by the economic reason. Hierarchical analysis of the structure of natural aggregation of forest areas by area showed the presence of five nested levels of heterogeneity and, accordingly, five groups of clusters. Depending on the level of division, the cluster analysis identifies nine hierarchical levels of area sizes of forest areas, and the level of their division is proportional to the scale - the smaller, the larger the scale of the study. This should be reflected in information about the state of forest areas in clusters C1-C3 (very large and large) and C4, C5 (medium and small) to develop effective management decisions.

\section{Key word:}

Forest fund, MAUP, forestry, area, hierarchical division.

\section{REFERENCES}

1. Ob utverzhdenii osnov gosudarstvennoy politiki $v$ oblasti ispolzovaniya, okhrany, zashchiti $i$ vosproizvodstva lesov $v$ Rossiiskoy Federatsii na period do 2030 goda. Rasporyazhenie pravitelstva Rossiiskoy Federatsii ot 26 sentyabrya 2013 goda no. 1724_r [On approval of bases of the state policy in the field of use, protection and reproduction of forests in the Russian Federation for the period till 2030. The order of the government of the Russian Federation on 26 September, 2013 no. 1724-p]. Available at: http://docs.cntd.ru/document/499047151 (accessed 2 October 2020).
2. Dobrinin D. Perspektivy vedeniya lesnogo khozyaistva s sokhraneniem postoyannogo lesnogo pokrova v Finlyandii i v Rossii [Prospects of forest management with the preservation of permanent forest cover in Finland and Russia]. Ustoychivoe lesopolzovanie, 2019, no. 1 (57), pp. 42-45.

3. Kovyazin V.F., Romanchikov A.Yu., Pasko O.A. Comparative analysis of forest landscadastral appraisal estimated with regards to wood and food resources. IOP Conference Series: Earth and Environmental Science, 2015. DOI: $10.1088 / 1755-$ $1315 / 27 / 1 / 012039$ 
4. Brockerhoff E.G., Barbaro L., Castagneyrol B., Forrester D.I. Gardiner B., González-Olabarria J.R., Lyver P.O'B., Meurisse N., Oxbrough A., Taki H., Thompson I.D Forest biodiversity, ecosystem functioning and the provision of ecosystem services. Biodiversity and Conservation, 2017, vol. 26, pp. 3005-3035.

5. Petkau V.V. Flexible and preventive forest management in Russia. Bulletin of the Chelyabinsk state University. Economy, 2009, vol. 1, no. 19 (157), pp. 127-136. In Rus.

6. Dobrinin D. O probleme vyyavleniya lesnykh uchastkov, na kotorykh vozmozhno ekonomicheski vygodnoe intensivnoe ekologicheski ustoychivoe lesopolzovanie [On the problem of identifying forest areas that can be economically profitable intensive and environmentally sustainable forest management] Ustoychivoe lesopolzovanie, 2012, no. 2, pp. 12-23.

7. Moiseev N.A. Forest economy as a branch science and its applied significance in the context of forest management reforms. Bulletin of the Moscow state University of forest. Lesnoy Vestnik, 2008, no. 5. In Rus. Available at: https://cyberleninka.ru/article/n/lesnayaekonomika-kak-otraslevaya-nauka-i-ee-prikladnoe-znachenie-vusloviyah-reform-lesoupravleniya (accessed 2 October 2020).

8. Lesnoy kodeks Rossiyskoy Federatsii ot 04.12.2006 no. 200_FZ red. ot 31.07.2020 [Forest code of the Russian Federation on 04.12.2006 no. 200-FZ (ed. from 31.07.2020)]. Available at: http://www.consultant.ru/document/cons_doc_LAW_64299 (accessed 02 October 2020).

9. Ob utverzhdenii Lesoustroitelnoy instruktsii (s izmeneniyami na 6 fevralya 2020 goda): Prikaz Ministerstva prirodnykh resursov ekologii Rossiiskoy Federatsii ot 29 marta 2018 goda no. 122 [On approval of the Forest Management instruction (as amended on February 6,2020). Order of the Ministry of natural resources and ecology of the Russian Federation of March 29, 2018 no. 122] Available at: http://docs.cntd.ru/document/542621790 (accessed 02.10 .2020 ).

10. Ob utverzhdenii normativov ploshchadi uchastkovykh lesnichestv, lesnykh kvartalov. Prikaz Federalnogo agentstva lesnogo khozyaistva ot 26 oktyabrya 2011 goda no. 447 [Approval of standards for the area of precinct forest areas and forest blocks. Order of the Federal forestry Agency of October 26, 2011 no. 447]. Available at: http://docs.cntd.ru/document/902321627 (accessed 2 October 2020).

11. Kovyazin V.F., Belyaev V.N., Pasko O.A., Romanchikov A.Yu. Taxation indices of forest stand as the basis for cadastral valuation of forestlands. IOP Conference Series: Earth and Environmental Science, 2014, vol. 21. DOI: 10.1088/1755-1315/21/1/012026

12. Pasko O.A., Tokareva O.S., Alshaibi A.J.A., Chernikova T.Y., Cabral P. Assessment of state of cedar forests in Tomsk region using remote sensing data of the Earth. Bulletin of the Tomsk Polytechnic University. Geo Assets Engineering, 2019, vol. 330, no. 1, pp. 98-109. In Rus.

13. Tokareva O.S., Pasko O.A., Majid S.M., Cabral P. Monitoring vegetation state in the central Iraq using Landsat- 8 satellite data Bulletin of the Tomsk Polytechnic University. Geo Assets Engineering, 2020, vol. 331, no. 6, pp. 19-31. In Rus.

14. Shawna J.D., Bram D. The modifiable areal unit problem (MAUP) in physical geography. Progress in Physical Geography, 2018, vol. 31 (5), pp. 471-479. DOI: 10.1177/0309133307083294

15. Applied Research Projects. Available at: https://www.espon.eu/ applied-research (accessed 2 October 2020).

16. Lee J.I., Cho W.K. The problem of variable area units in hedonistic models of housing prices. Urban Geography Phys., 2016, vol. 37 (2), pp. 223-245. Available at: https://dialnet.unirioja.es/ servlet/articulo?codigo=5466483 (accessed 2 October 2020).

17. Vas D.D., Nelson A., Gibson H.S., Temperley V., Lieber A. Global map of travel time to cities to assess inequality in accessibility in 2015. Nature, 2018, vol. 553 (7688), pp. 333-336. Available at: https://doi.org/10.1038/nature25181 (accessed 2 October 2020).

18. Gilbert M., Nicolas G., Cinardi G., Van Boeckel T.P., Vanwambeke S.O., Wint G.R.W.W. Global distribution data for cattle, buffaloes, horses, sheep, goats, pigs, chickens and ducks in 2010. Scientific Data, 2018, vol. 5 (1), pp. 1-11. Available at: https://doi.org/10.1038/sdata.2018.227 (accessed 2 October 2020).

19. Beckel V. Robinson intensive poultry farming in Thailand. Agricultural industry. Available at: https://doi.org/10.1016/j.agee. 2011.12.019 (accessed 2 October 2020).
20. Cebrecos A., Domınguez-Berjon M.F., Duque I., Franco M., Aggregated indicators of deprivation in various spatial units of health research. Applied geography, 2018, vol. 95, pp. 9-18. Available at: https://doi.org/10.1016/j.apgeog.2018.04.001 (accessed 2 October 2020).

21. Truong P.N., Stein A. Hierarchically adaptable spatial regression model for the Association of aggregated health status data and environmental data. Spatial statistics, 2018, vol. 23, pp. 36-51. Available at: https://isiarticles.com/bundles/Article/pre/pdf/ 161686.pdf (accessed 2 October 2020).

22. Utazi C., Thorley J., Alegana V., Ferrari M., Nilsen K., Takahashi S. A spatial regression model for the disaggregation of areal unit based data to high-resolution grids with application to vaccination coverage mapping. Statistical Methods in Medical Research, 2018. Available at: https://doi.org/10.1177/0962280218797362 (accessed 2 October 2020).

23. Cebrecos A., Dominguez-Berjon M.F., Duque I., Franco M., Escobar F. Geographical and statistical stability aggregated indicators of deprivation in various spatial units of health research. Applied geography, 2018, vol. 95, pp. 9-18.

24. Tatem A.J. World Pop, open data for spatial demography. Scientific Data, 2017, vol. 4. Available at: https://doi.org/10.1038/ sdata.2017.4 (accessed 12 April 2020)

25. Salas-Olmedo M.H., Moya-Gomez B., García-Palomares J.C., Gutierrez J. Digital trail of tourists in the cities: comparison of big data sources. Tourism management, 2018, vol. 66, pp. 13-25. Available at: https://doi.org/10.1016/j.tourman.2017.11.001 (accessed 2 October 2020).

26. Garcia-Llamas P., Calvo L., De la Cruz M., Suarez-Seoane S. Landscape heterogeneity as a surrogate biodiversity in mountain systems: which spatial analytical unit is most appropriate? Environmental indicator, 2018, vol. 85, pp. 285-294. Available at: https://doi.org/10.1016/j.ecolind.2017.10.026 (accessed 2 October 2020).

27. Wu J., Levin S.A. A patch-based spatial modeling approach: conceptual framework and simulation scheme. Ecological Modelling, 1997, vol. 101, pp. 325-346.

28. WangYa., Di Q. Modifiable areal unit problem and environmental factors of COVID-19 outbreak Affiliations expand PMID. Total Environ, 2020. Available at: https://pubmed.ncbi.nlm.nih.gov/ 32534259 (access 2 October 2020).

29. Nelson J.K., Brewer C.A. Evaluating data stability in aggregation structures across spatial scales: revisiting the modifiable areal unit problem. Cartography and Geographic Information Science, 2017, vol. 44 (1), pp. 35-50. Available at: https://doi.org/10.1080/ 15230406.2015.1093431 (accessed 2 October 2020).

30. Zaharchenko A.V., Alekseev V.I., Ipatova D.V. Hierarchical concept of soil heterogeneity and planning the scale of research. Bulletin of the Tomsk Polytechnic University. Geo Assets Engineering, 2016, vol. 327, no. 4, pp. 149-163. In Rus.

31. Alekseev V.I. Wavelet analysis of the dynamics of changes in the El niño-La niña phenomenon and its prediction. Bulletin of Ugra State University, 2018, vol. 3 (50), pp. 75-87. In Rus. DOI: 10.17816/byusu2018075-87

32. Pasko O.A., Zakharchenko A.V., Pospelova E.V. Area differentiation of agricultural land on the example of Tomsk district. Bulletin of the Tomsk Polytechnic University. Geo Assets Engineering, 2019, vol. 330, no. 5, pp. 100-112. In Rus.

33. Kovyazin V.F., Martynov A.N., Belyaeva N.V. Osnovy lesnogo khozyajstva i taksatsiya lesa [Fundamentals of forestry and forest taxation]. Moscow, St-Petersburg, Krasnodar, Lan Publ., 2017. $238 \mathrm{p}$.

34. Sayt Departamenta lesnogo khozyaystva Tomskoy oblasti [Website of the Department of forestry of the Tomsk region]. Available at: https://deples.tomsk.gov.ru (access 2 October 2020).

35. Phillips J.D., Marion D.A. Biomechanical effects, lithological variations, and local pedodiversity in some forest soils of Arkansas. Geoderma, 2005, vol. 124, pp. 73-89.

36. Pasko O.A., Kovyazin V.F., Zakharchenko A.V., Lebedeva N.A Spatial organization of forestfund. IOP Conference Series: Earth and Environmental Science, 2020. DOI: https://iopscience.iop. org/article/10.1088/1755-1315/574/1/012061 


\section{Information about the authors}

Olga A. Pasko, Dr. Sc., Cand. Sc., professor, head of the Sector of Experimental Agricultural Technologies, Agrophysical Research Institute.

Alexander V. Zakharchenko, Dr. Sc., leading researcher, Tyumen scientific center of the Siberian branch of the Russian Academy of Sciences.

Vasily F. Kovyazin, Dr. Sc., professor, Saint Petersburg mining University. 